\title{
12 \\ Can We Dig It? Archaeology of Ancestral Polynesian Society in Tonga: A First Look from Falevai
}

Sean P. Connaughton

\author{
Department of Archaeology \\ Simon Fraser University \\ 8888 University Drive \\ Burnaby, British Columbia \\ V5A 3R5 Canada \\ spconnau@sfu.ca
}

\section{Introduction}

Polynesian culture has long captivated the attention of both academic researchers and the wider public. A primary interest for archaeologists has been the explanation and understanding of the development of Polynesian cultures, which it has been proposed, have their roots in an ancestral homeland situated in western Polynesia and more specifically Tonga and Samoa (Burley 1998; Groube 1971; Kirch 1984, 1997; Kirch and Green 2001). However, an ongoing debate in Pacific anthropology is whether archaeologists can convincingly identify and explain the historical trajectory of an Ancestral Polynesian Society (APS) (Kirch and Green 2001; Smith 2002). Kirch and Green (2001) argue that Western Polynesian culture developed from a founding Eastern Lapita base and succeeding Ancestral Polynesian Society. The most visible cultural marker distinguishing these ancestral Polynesians is plain earthenware pottery, which characterises archaeological assemblages for a millennium following the Lapita phase. Smith (2002) on the other hand, has asserted that the archaeological evidence does not support the concept of a specifically proto-Polynesian ancestral society in Western Polynesia during the ceramic phase.

Critical to understanding ancestral Polynesian development is the sequence of ceramic transition from the colonising Eastern Lapita phase to the subsequent Polynesian Plainware phase. I contend that this archaeological transition and succeeding development of Ancestral Polynesian Society in the Polynesian Plainware phase reflects internal social and economic change, with limited influence from groups outside of Tonga. This paper outlines recent arguments for a Polynesian Homeland being evident in Tonga and Samoa as well as presenting an overview of fieldwork undertaken in 2005 at the Lapita/Polynesian Plainware site 


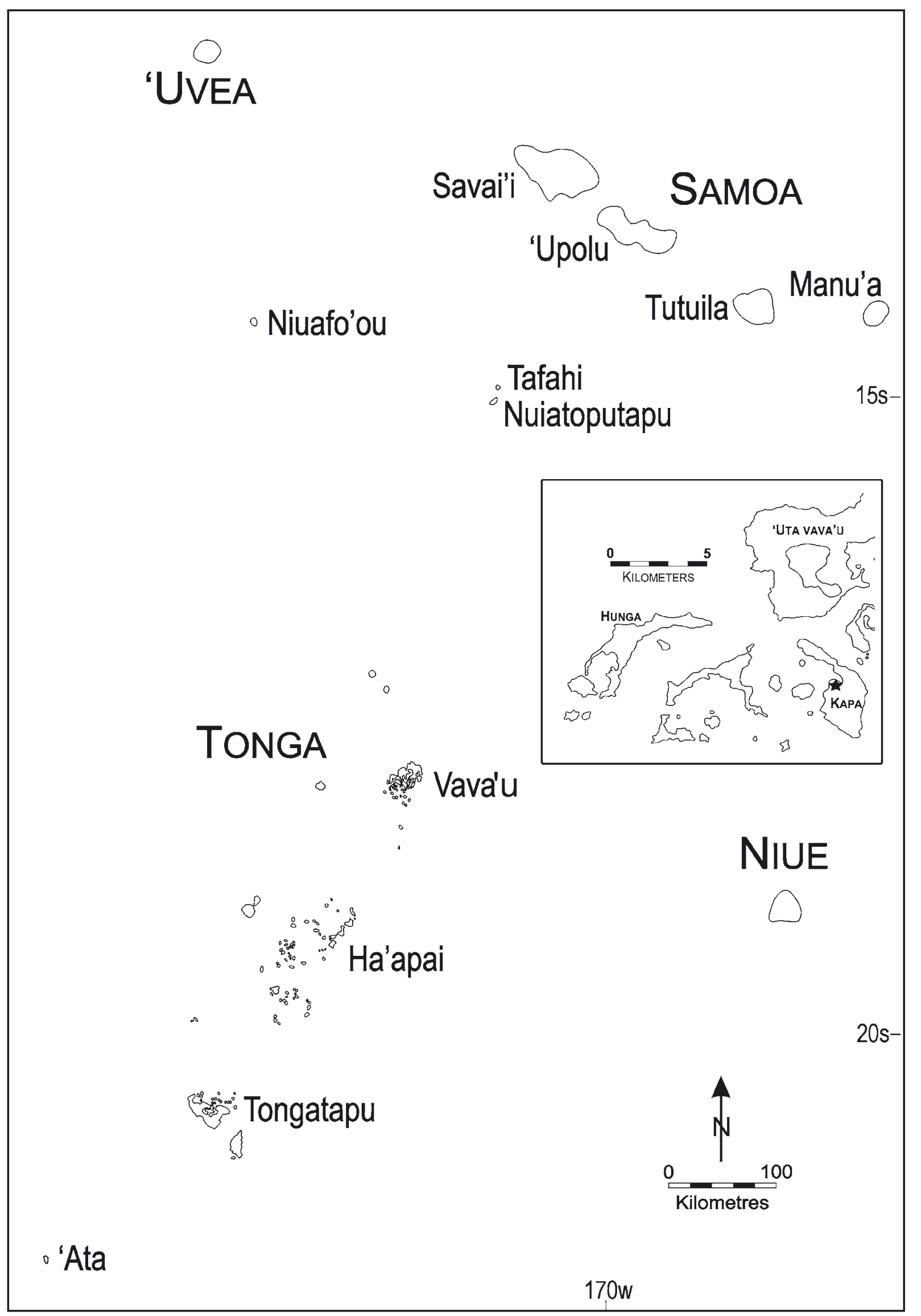

Figure 1. Tonga, Samoa, 'Uvea and Niue. Inset shows Kapa Island, Vava'u. 
of Falevai in the Vava'u group, Kingdom of Tonga. The data from the latter are not yet fully analysed, but do point towards new insights into regional considerations of the Polynesian Plainware phase.

\section{Background}

The Kingdom of Tonga comprises over 160 islands on the western flank of the Polynesian triangle with Fiji to the west and Samoa to the northeast (Figure 1). Three main island groups, Tongatapu, Ha'apai, and Vava'u, make up the archipelago; volcanic islands and sea mounts form the Tofua Volcanic Arc to the west. Most inhabited islands are coral limestone formations lying on the eastern non-volcanic chain sitting atop the submerged Tonga Ridge.

Tonga has a lengthy culture history, beginning with colonisation by Austronesian-speaking Lapita peoples approximately $2850 \mathrm{BP}$ (Figure 2). The Lapita phase is defined by the distinctive dentate-stamped decorated earthenware pottery, which has a distribution range from the Bismarck Archipelago to West Polynesia (Kirch 1997). In Tonga, most decorated pottery has been defined and labeled Eastern Lapita and is characterised by markedly simplified Lapita motifs when compared to Lapita motifs in Fiji and further west (Burley et al. 2002; Kirch 1997). However, Western Lapita motifs have been identified in Tonga during the initial settlement period (Burley and Dickinson 2001).

During the Polynesian Plainware phase, social transformation and cultural adaptation including aspects such as settlement dispersal, population growth and development of dryland agriculture, presumably contributed to the emergence of an Ancestral Polynesian Society that developed over the course of the next 1000 years. This ancestral culture was the template for later Polynesian societies who eventually explored and ultimately colonised all of the islands of the Polynesian triangle (Burley 1998:337; Kirch 1997; Kirch 2000). This paper focuses on the small but significant slice of time, the transition from the Eastern Lapita phase to the subsequent Polynesian Plainware phase as represented at Falevai.

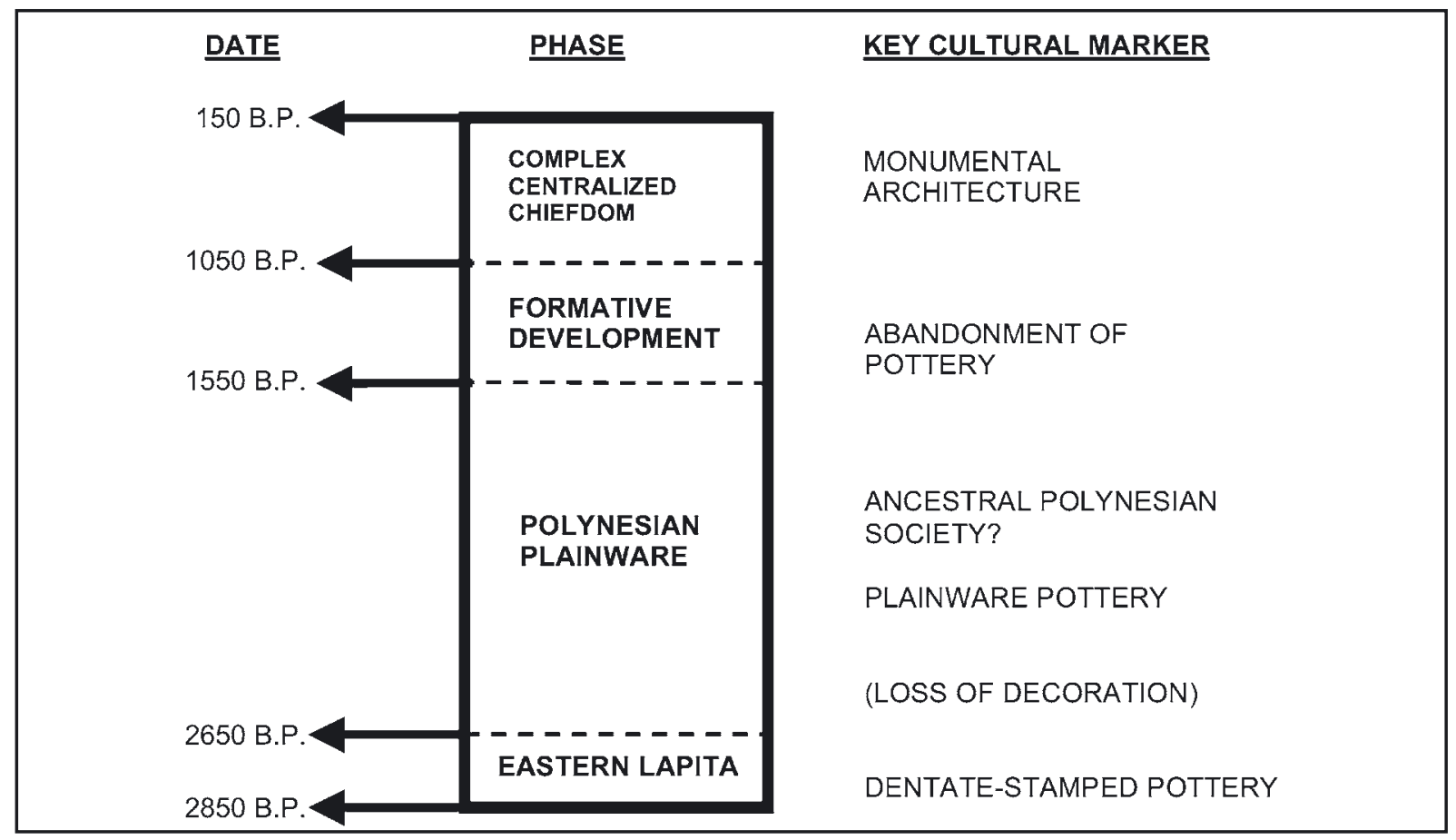

Figure 2. Culture history of Tonga (after Burley 1998). 


\section{"Ancestral Polynesian Society"?}

Following the lead of earlier anthropologists (Flannery and Marcus 1983; Taylor 1948; Sapir 1916), Kirch and Green (2001) employ archaeological, ethnographic, biological and linguistic data to reconstruct aspects of Ancestral Polynesian Society. They outline in detail the arguments and evidence found in the archaeological record in West Polynesia that support the concept of an Ancestral Polynesian Society that developed from Lapita ancestry (Kirch and Green 2001). They argue that it is largely through in situ development and transformation, involving factors such as population growth, settlement dispersal and changing subsistence practices which contribute to the emergence of an Ancestral Polynesian Society. They outline a range of distinctive material culture including plainware pottery, shell adzes, fishhooks, beads, rings, and basalt adzes which is seen as being associated with Ancestral Polynesian Society (Kirch and Green 2001:163-200). At the same time they highlight a much wider range of material objects used in traditional Polynesian society which were made of wood, bamboo, bark, fiber, leaves, cordage and feathers and have not survived. With this taphonomic aspect in mind they emphasise that archaeology does not, or is it ever likely to tell us everything there is to know (Kirch and Green 2001:164-165). They also note that archaeological research into sites associated with Ancestral Polynesian Society are generally characterised by limited test excavations rather than extensive horizontal investigations. They emphasise the need for undertaking large areal excavations of these sites if we are to move beyond our current understanding (Kirch and Green 2001:83).

Contrary to the claims of Kirch and Green, Smith asserts that the early archaeological record is insufficient to claim an Ancestral Polynesian homeland in Western Polynesia stating that "there is no necessary chronological relationship between the early archaeology of the region and the origins of the socio-cultural characteristics that have been used to identify a society as Polynesian" (Smith 2002:195). While Smith (2002:188) acknowledges the viability of the model of the development of Ancestral Polynesian Society from an ancestral Lapita base, her contention is that the archaeological data in support of such a model is not visible. Furthermore, she claims that the ceramic sequence transition from decorated pottery to completely undecorated pottery in the Polynesian Plainware phase reflects a continuum of pottery technology with no social or economic implications. The assertion that Ancestral Polynesian Society developed in the early stages of colonisation and is manifest during the Plainware Phase is unsupported in Smith's view.

Smith's (2002) focus was on an assessment of separate artefact classes (i.e., ceramics, adzes, and fishhooks) rather than the cultural package as a whole. There are certainly gaps in the archaeological record, as emphasised by Kirch and Green $(2001: 83,165)$ and Smith did not have access to non-analysed plainware vessel data sets, but to claim that the archaeological record is unable to adequately assess change over time ignores a millennium's worth of locally manufactured pottery in West Polynesia. A more detailed ceramic chronology is certainly required for a full understanding of the Polynesian Plainware phase and the possible emergence and development of Ancestral Polynesian Society and as Smith (2002:146) proposed a site with a late Lapita or a transitional Polynesian Plainware assemblage is a necessary starting point. Falevai in the Vava'u Group of Tonga provides this starting point for documenting change during the transition and up until the end of the Polynesian Plainware phase when pottery was abandoned.

\section{The Importance of Polynesian Plainware Pottery Studies}

My investigation of the plainware component of Lapita assemblages and subsequent plainware assemblages, in corroboration with economic and population data, will eventually provide further insights into the emergence of an Ancestral Polynesian Society in Tonga. Our current inability to fully understand or explain the anthropological 
significance of the transition from Lapita decorated ware to Polynesian Plainware is in large part due to a complete lack of focus in the study of plainware ceramics. Generally identified as utilitarian ware, plainware is often considered mundane in comparison to decorated Lapita vessels. As a consequence, plainware has been neglected in archaeological studies in the Pacific as a whole (Burley 1998; Kirch 2000). Decorated pottery sherds rarely make up more than 4-5\% of a Lapita vessel assemblage in Tonga (Burley et al. 2002), yet they have customarily been the major focus of archaeological inquiry (Kirch 2000:102). With the exception of Niuatoputapu, we know relatively little about the Plainware phase and its ceramic sequence through Tongan prehistory (Burley 1998; Kirch 1988).

\section{Polynesian Plainware: The ceramics of Ancestral Polynesian Society}

Investigations conducted by Burley (1998), Dye (1996), Green (1972, 1986), Groube (1971), Kirch (1988), Poulsen (1987), and Spennemann (1989) provide the current basis for classifying Polynesian Plainware pottery. Such vessels represent a continuing tradition of pottery production from the founding Eastern Lapita phase. Polynesian Plainware is characterised by a limited range of vessel form and decoration is virtually absent (Burley 1998; Dye 1996; Kirch 1988).

Plain pottery is considered a utilitarian ware (Burley 1998:361; Kirch and Green 2001:168), and was most likely used for storage, serving and possibly cooking (Spennemann 1989). Three vessel forms are reported to have been retained in Tonga; (1) subglobular jars with a slightly restricted orifice and narrowing below the rim; (2) simple cups; and (3) bowls (Burley 1998:361). Dye's (1996) analysis of Plainware variation on Tongatapu and Lifuka demonstrated an increasing shift from vessel forms with an everted rim orientation to a more vertical orientation. In conjunction, there was a steady decline over time in bowl frequencies while subglobular pots increased in frequency.

At the same time, when Fijian Plainware from the Sigatoka Sand Dune site in Viti Levu is compared with Tongan Plainware, the Fijian Plainware assemblages diversify in terms of form, decoration and manufacturing while the Tongan Plainware remains relatively homogeneous before disappearing altogether (Burley 2005). Tongan Plainware invokes a pan-Tongan flavor across the archipelago, potentially resulting from the combined effects of isolation from outside influence and the development of a stronger shared local identity. Ultimately, the production of Tongan Plainware and pottery altogether ceases around 1550 BP while Fijian Plainware continues to be made through to $1450 \mathrm{BP}$ when it is replaced by the Navatu phase style in western Fiji approximately (Burley 2005).

\section{Associated Developments during the Polynesian Plainware Phase}

The transition from a Lapita occupation to Polynesian Plainware phase is demarcated predominantly by the loss of decorated ceramics, mainly dentate-stamping, in conjunction with the loss of certain vessel forms (e.g., collared jars). Lip notching, rim thickening and changes in wall thickness might also occur (Kirch and Green 2001). Nevertheless, it is not just the ceramics that are changing, other significant changes are apparent in settlement and subsistence patterns, site distribution, and population growth during the Plainware phase in Tonga (Burley 1998; Burley in press; Spennemann 1989). Evaluating these avenues of inquiry provide a more holistic framework from which to interpret the archaeological record and better understand how ancestral Polynesian culture developed through time.

It is argued that during the Polynesian Plainware phase, populations continue to grow and settlements stretch beyond the shoreline to inhabit the interior of larger islands throughout Tonga as well as offshore islands and outliers. The widespread distribution of ceramics, suggests an expansive if not full use of the landscape by the end of the Plainware phase (Burley in press; Spennemann 1989). Recent work in the Vava'u Group by Burley (Burley this volume) certainly demonstrates this trend. Earlier Lapita sites were not being abandoned as continuous occupation does occur on most of these sites. In some cases, there is evidence suggesting there has 
been an expansion of site size from small hamlets to larger village size complexes (Burley in press). However, the limited number of Lapita sites reported from Vava'u, in comparison to Tongatapu and Ha'apai, suggests a more limited number of people traveling northward (Burley this volume).

With growing populations inhabiting most of the islands in the Tongan Archipelago by the onset of the Polynesian Plainware phase, dry land agriculture intensifies across the Tongan landscape with less reliance on natural resources (Burley 1998:362-363). Spennemann (1989) documented and recovered copious quantities of pottery across the interior of Tongatapu which points to settlement expansion into the interior along with an associated increase in intensive dry-land agriculture. Foraging on the reef continues, but the dominant role it once played in initial Lapita settlement now seems to be diminished. During initial Lapita settlement, indigenous fauna, particularly iguanas and birds, became extirpated and in some cases extinct (Steadman $e t$ al. 2002a:3677; Steadman et al. 2002b) and shellfish and turtle were also heavily exploited (Spennemann 1989). Comparative analysis of faunal assemblages from both Lapita and Plainware sites will further enhance our understanding of changing subsistence practice.

These shifts in human behavior have implications for the emergence of an Ancestral Polynesian Society, whereby an increase in human populations and developmental adaptations within the Tongan environment convey a changing mode of life. The ceramic transition is critical, not just for demarcating some arbitrary boundary for culture history purposes, but for the underlying social changes it reflects (Burley 1998).

\section{Falevai}

The site of Falevai is situated on the southwest leeward shore of Kapa Island located in the Vava'u Group (Figure 1 inset). The site shares its name with the nearby village of Falevai, but occurs on land known as vakataumai, which refers to the ease at which one can bring a canoe ashore. Falevai is situated approximately $50 \mathrm{~m}$ from the sea and sits atop a prehistoric back beach dune that was capped with coral gravel infill.

An initial $1 \times 1 \mathrm{~m}$ test unit was excavated by Burley in 2003 to assess ceramic period occupation and stratigraphy. Based on ceramics recovered from the test unit, Falevai was identified primarily as a Polynesian Plainware phase site with a relatively shallow Eastern Lapita phase component in the lowest levels. No charcoal samples were obtained for radiocarbon dating from this test unit. A small number of decorated sherds $(n=9)$ were recovered from the bottom levels of the test unit that reached a depth of $2.2 \mathrm{~m}$. Given the shallow Lapita occupation level and ensuing metre or so of Polynesian Plainware ceramics, Falevai was seen as an ideal site to potentially document first settlement by Lapita people and the subsequent transformations to the end of the Polynesian Plainware phase.

In the summer of 2005, I excavated a $3 \times 4$ m block unit at Falevai to document first settlement and determine the time frame in which decorated Lapita pottery disappears from the archaeological record. A further aim was the establishment of a detailed ceramic chronology that equated with Ancestral Polynesian Society. The Falevai data set could then be compared with three other ceramic sites from across the Tongan Archipelago to control for change across space and time (Figure 3).

Falevai was excavated contiguously in block units comprising eleven $1 \times 1 \mathrm{~m}$ square units to control for stratigraphic breaks and feature exposures. Each unit was excavated by trowel and shovel in arbitrary levels of $10 \mathrm{~cm}$ and dry sieved through both $6.4 \mathrm{~mm}$ and $3.2 \mathrm{~mm}$ mesh sieves. Due to time constraints and previous site knowledge supplied by Burley, the first $90 \mathrm{~cm}$ was expediently removed and not screened with the exception of Unit 2, which was excavated in the above fashion as a control unit. The control unit confirmed initial interpretations that the upper $50 \mathrm{~cm}$ of the deposit was aceramic and that it largely contained fill deposit with little in the way of material culture. A $50 \times 50 \mathrm{~cm}$ shell column sample was removed in $10 \mathrm{~cm}$ intervals and dry sieved through both $6.4 \mathrm{~mm}$ and $3.2 \mathrm{~mm}$ mesh sieves. We also collected all pottery from this same shell column which was left unwashed for future residue analysis. 


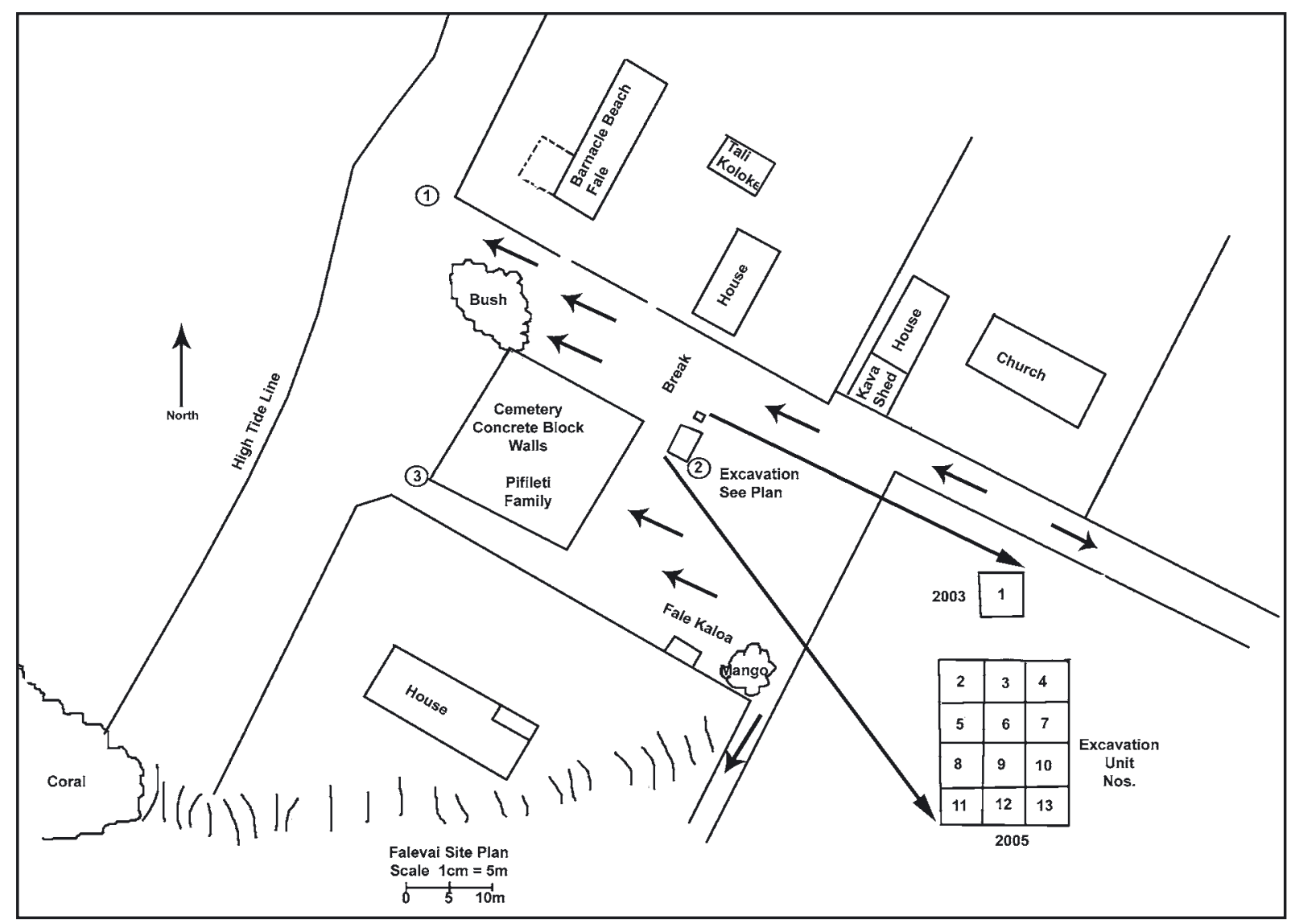

Figure 3. Falevai site plan and excavations.

\section{Stratigraphy}

The stratigraphy at Falevai is relatively homogenous overall, yet four distinct strata have been identified (Figure 4). Strata have been labelled from I-IV from the uppermost sod layer to the lower sterile deposit (Table 1). Pit features, umu features and post-holes were noted in profile and plan view. Unit 2 displayed a pit feature intruding into the lowest levels of Stratum IV containing Stratum III matrix originating from the Polynesian Plainware occupation levels. This feature appears to have been responsible for disturbing the context of the lower levels in Unit 2 and thus displacing dentate-stamped Lapita sherds $(n=4)$ into the upper levels of the later Polynesian Plainware phase.

With the exception of Unit 2, the overall stratigraphy within Stratum III and IV at Falevai seemed to be relatively undisturbed providing good context for evaluating ceramic change through time. From my preliminary analysis thus far, I have noticed that the condition in which pottery is recovered from the lowest level compared with the upper-most levels reveal patterns of decreasing sherd size due to degradation, weathering and human impact on the landscape. While Stratum IV to the mid levels of Stratum III yield an abundance of well-preserved pottery, the very upper levels of Stratum III show a decrease in sherd frequency and size. Stratum II contains pottery sherds intermixed with some historic artifacts and coral gravel infill, but they are highly degraded and crumbsherd in size. My impression is that the very upper levels of Stratum III and particularly Stratum II, represent the aceramic period when pottery production was abandoned in Tonga. Although I do not have a representative date for this period at Falevai, at the site of Otea also on Kapa Island, Polynesian Plainware phase ceramics are capped and separated from aceramic strata by a very compact shell layer. This cap has been dated at $1615 \pm 35 \mathrm{BP}$ and establishes the date of loss of ceramics at the end of the Plainware phase (Burley and Connaughton in press). 


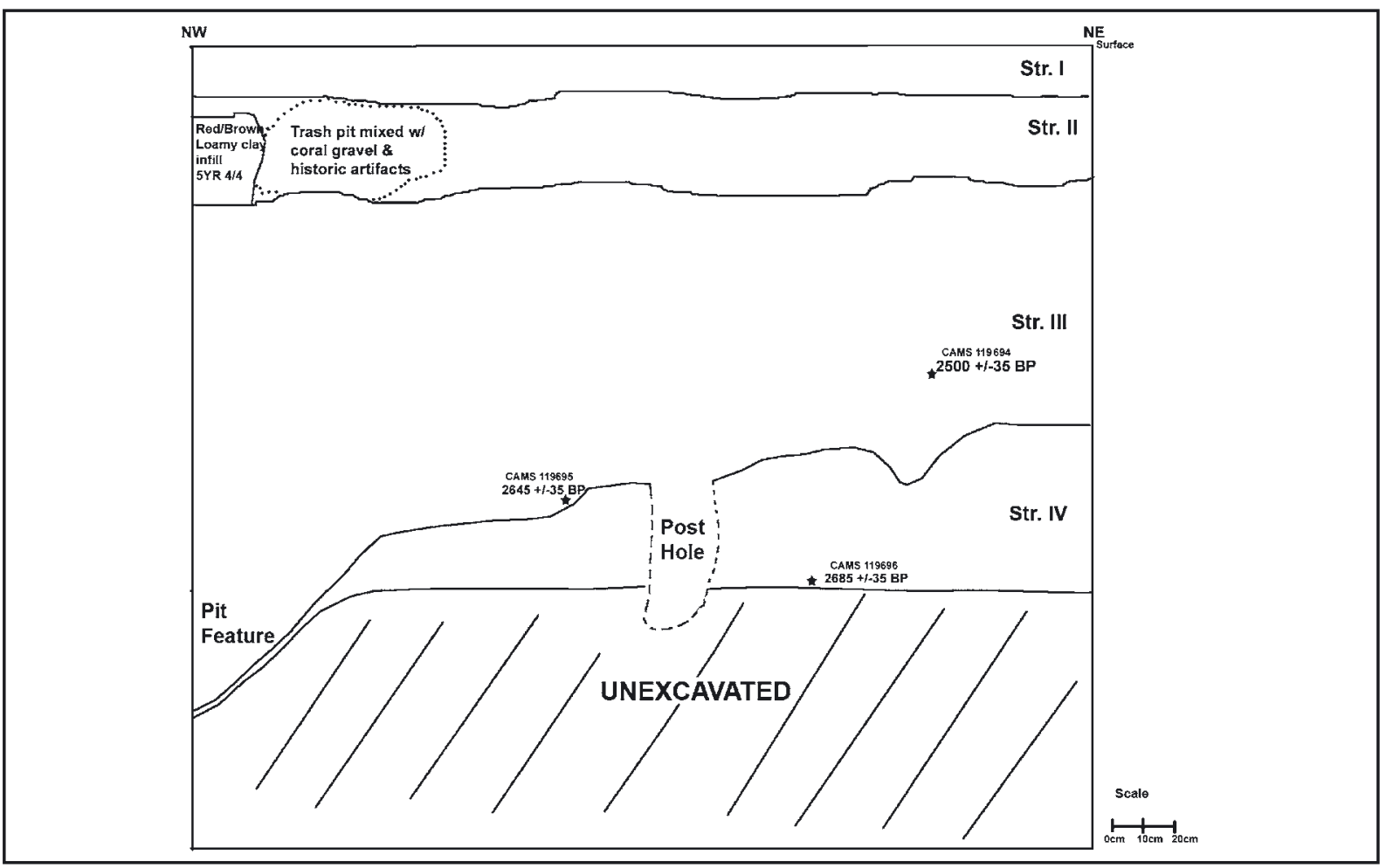

Figure 4. Falevai north wall profile.

Table 1. Stratigraphy description of Falevai.

\begin{tabular}{|c|c|c|c|}
\hline Stratum & $\begin{array}{l}\text { Max. Depth } \\
\text { cm BS }\end{array}$ & $\begin{array}{l}\text { Munsell } \\
\text { Color }\end{array}$ & Description \\
\hline I & 18 & 5 YYR 3/1 & Very dark gray topsoil with roots and very small traces of shell and historic artefacts. \\
\hline II & 52 & $7.5 Y R 3 / 2$ & $\begin{array}{l}\text { Dark brown, loamy soil with coral gravel infill creating a flat surface prehistorically. } \\
\text { Some historic artefacts are intermixed such as glass, nails and ceramics but is mainly } \\
\text { isolated in trash pit seen in profile; some pottery but highly degraded and very small. }\end{array}$ \\
\hline III & 218 & $7.5 Y R 4 / 2$ & $\begin{array}{l}\text { Dark brown/brown loamy/clay soil mixed with coral, shellfish (broken and whole), rocks and } \\
\text { pumice. Fauna is relatively low in frequency and comprised mainly of fish. Pottery is recovered } \\
\text { in high volume, particularly Plainware with rims and potstand fragments. This stratum is } \\
\text { quite homogenous and appears to be a solid representation of plainware occupation. }\end{array}$ \\
\hline IV & 220 & $2.5 Y 7 / 4$ & $\begin{array}{l}\text { Pale yellow sand with coral and pumice; some shellfish } \\
\text { and very small amounts of pottery were recovered from } \\
\text { the top of this stratum, otherwise, culturally sterile. }\end{array}$ \\
\hline
\end{tabular}

\section{Falevai Plainware Pottery}

It is premature to present an in-depth detailed analysis of the plainware pottery at Falevai during the Plainware phase for this paper. However, I can provide insights and patterns that have emerged from my preliminary investigation in an attempt to characterise the ceramic assemblage. A sherd level of analysis was undertaken for the purpose of this paper focusing primarily on vessels forms.

A total of 10,155 sherds were recorded from Falevai with 552 representing plain rim sherds and another 42 decorated rim sherds (Table 2). Decorated rim sherds account for $7 \%$ of the total rim assemblage. Only jars were identified as having been decorated, no bowls displayed any decoration. Decoration on rim sherds is largely restricted to the to the lip with occasional instances on the neck. Of these decorated sherds, dentate- 
Table 2. Sherd inventory from Falevai.

\begin{tabular}{lccccccccc}
\hline & $\begin{array}{c}\text { Dec. } \\
\text { Rim }\end{array}$ & $\begin{array}{c}\text { Dec. } \\
\text { Neck }\end{array}$ & $\begin{array}{c}\text { Dec. } \\
\text { Shoulder }\end{array}$ & $\begin{array}{c}\text { Dec. } \\
\text { Body }\end{array}$ & $\begin{array}{c}\text { Plain } \\
\text { Rim }\end{array}$ & $\begin{array}{c}\text { Plain } \\
\text { Neck }\end{array}$ & $\begin{array}{c}\text { Plain } \\
\text { Shoulder }\end{array}$ & $\begin{array}{c}\text { Plain } \\
\text { Body }\end{array}$ & Total \\
\hline Falevai $12 \mathrm{~m}^{2}$ area & 42 & 6 & 1 & 12 & 552 & 81 & 20 & 9441 & 10155 \\
\hline
\end{tabular}

stamping is represented by ten sherds and is found predominantly in the lower levels of the unit, corresponding with the initial Lapita phase. A small number $(n=4)$ of dentate-stamp sherds do occur in the upper Polynesian Plainware phase but this is most likely due to disturbance caused by umu construction, post-hole insertions and pit features. In comparison, finger-notch impressed and incised sherds accounted for 33 and 7 sherds respectively and correlate within the transitional horizon from Lapita into the Polynesian Plainware phase. It is interesting to note the frequency of finger impressed decorated sherds relative to dentate-stamped sherds for it suggests that dentate-stamped decoration was on the decline and was abandoned soon after initial occupation. Meanwhile, decorated finger-notch impression sherds presumably continued into the early Polynesian Plainware phase, along with the production of fully plainware vessels, before being abandoned.

A limiting factor in the analysis of Plainware sherds is the almost total lack of complete reconstructable vessel forms due to the small size of sherds. Typically, rim sherds account for no more than $5-10 \%$ of the complete rim of a vessel. This is the norm in Pacific sites, yet the most precise information about vessel forms is usually ascertained from rim sherds. Rim sherd analysis provides data on rim orientation, rim diameter, lip form and lip thickness. I will briefly describe different vessel forms that characterise the ceramic assemblage at the present time.

Jars dominate the assemblage at Falevai, with a variety of forms of jars having been identified (Figure 5). The most conspicuous attribute of a jar is its neck. The first type, described by Burley (1998:361) and others (Groube 1971; Kirch 1988; Poulsen 1987), is a relatively thin-walled, subglobular jar with restricted orifice and slightly to strongly inverted rim orientation. Rim diameters range from 10-44 cm. The second type of jar resembles a "fishbowl" like form, with relatively thin walls and restricted orifice but the degree of rim orientation appears more strongly inverted than the first type of jar described. Rim diameters range from 10$28 \mathrm{~cm}$. Short-neck jars make up the third form and are constituted by a neck less than $3 \mathrm{~cm}$ in length from the lip. They appear to have a subglobular form with restricted orifice and slightly inverted rims. Rim diameters range from $10-26 \mathrm{~cm}$. The fourth type is collared jars. A collar usually begins at the point of maximum diameter, or at a slight restriction close to it, and the orifice is not significantly reduced relative to the body (Rice 1987). Rim diameters range from $16-26 \mathrm{~cm}$. Plain collared jars appear to be retained into the early Polynesian Plainware phase but soon drop out of the record altogether. The other three jar forms are found throughout the Plainware phase. Overall, inverted rims account for $82 \%$ of total vessel rim orientation amongst plainware jars that tend to be slightly to strongly inverted. Quantifying the degree of invertedness has yet to be undertaken at this time. Simple bowl vessel forms represent $3 \%$ of the total plain rim assemblage. Most had a slightly everted to straight rim orientation. Only fourteen rim sherds were identified as bowls. Rim diameters for bowls range from $14-26 \mathrm{~cm}$.

There is no evidence that Plainware vessels were used for cooking. The occurrence of soot would provide solid evidence that a pot was used directly over a fire. Soot is usually most prevalent at the shoulder and maximum diameter of a vessel, rather than at the base (Hally 1983:8). Recording instances of soot deposition and their placement on the vessel allow for inferences as to how the pot was positioned relative to the fire. No such evidence was found within the Falevai assemblage. Furthermore, evidence for spalling, due to leaching and cracking while being heated, as well as pedestalled temper, due to the stirring or scraping motion of utensils against the walls of the pot (Rice 1987), was also not observed. Moreover, the high frequency of non- 


\section{Thin-walled Subglobular Jars}
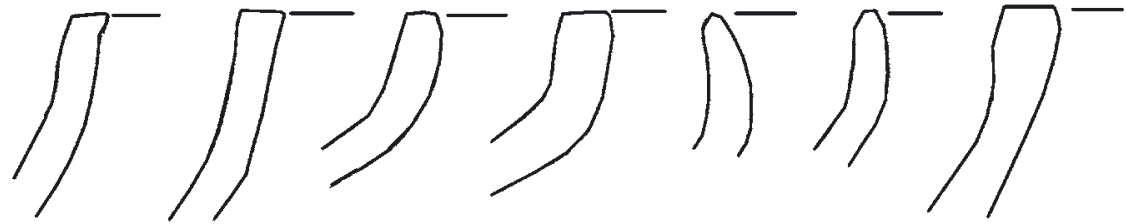

\section{Inverted "Fishbowl" Jars}

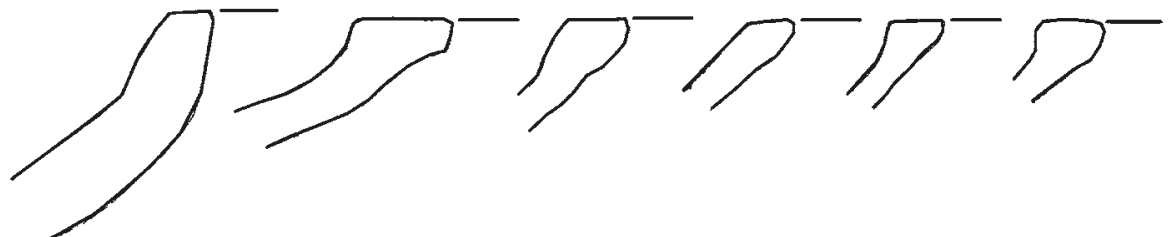

Short-neck Jars

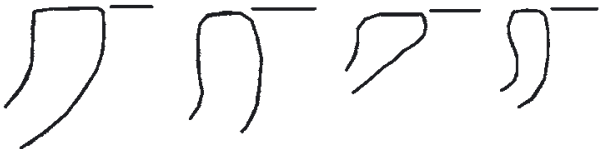

\section{Collared Jars}
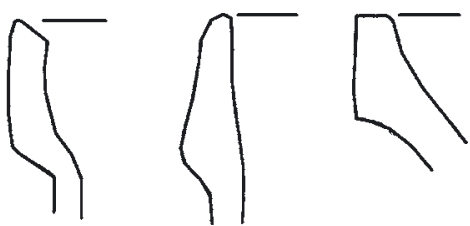

\section{Bowls}
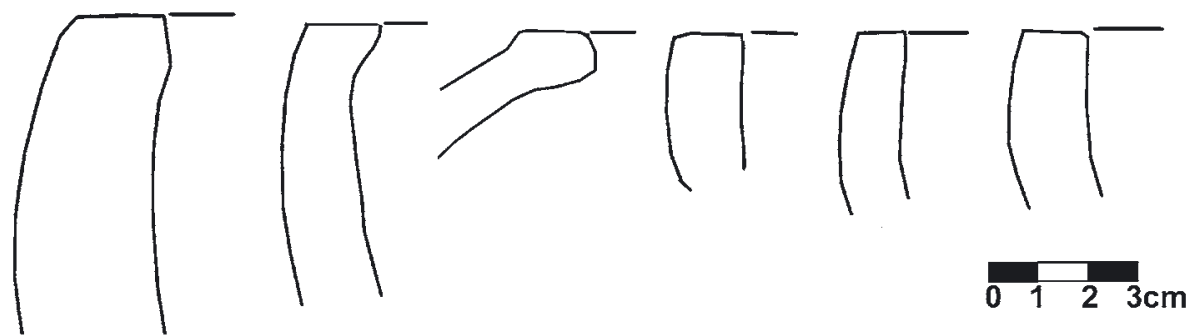

Figure 5. Vessel form types from Falevai.

cooking jar vessel forms $(n=172)$ and the limited amount of bowls represented $(n=14)$, suggests that these vessels were used primarily for storage. What was exactly being stored has yet to be established and is a topic that may be examined in future research.

Ultimately, my Ph.D. research will provide a comprehensive ceramic analysis from Falevai, as well as a selection of other Plainware phase sites excavated by Burley since 1990. Included are Tongoleleka, Ha'ateiho, and Holopeka. It is too early to discern the detailed nuances of plainware pottery present in Tonga during the Plainware phase for this paper. Nevertheless, my initial impression from Falevai is that whilst the loss of decoration was relatively rapid after initial colonization, a range of plainware pots retaining certain distinctive vessel and rim forms continued at first before a shift to decreasing diversity and variation over time. Manufacturing techniques such as paddling and wiping appear common amongst recovered plainware sherds. Within the plainware levels, pot-stand fragments $(n=6)$ of various shapes and sizes were recovered along with the addition of unfamiliar forms and thicker pieces of pottery. Again, further analysis is needed to assess vessel form variation and use through time. 


\section{Non-ceramic data}

Non-ceramic artifacts have been sorted and counted but not analysed in any detail (Table 3). Shell valuables dominated by shell bracelet/ring fragments are present throughout Lapita and Plainware occupations. Octopus lure parts are represented by cut Cypraea tops and in two cases, the top of the Cypraea has been shaved down very cleanly. A variety of tools made of pumice and coral are present but andesitic-basalt tools occur most frequently. A total of eight basalt adze fragments were recovered along with two whole adzes; one from both the Plainware (Type Va) and Lapita (Type IIIb) levels (Green and Davidson 1969). Based on color (Burley this volume), it is likely that the two whole adzes are from Late, a volcanic outlier to the south and west of Vava'u. However, all the basalt artifacts have yet to be sourced using $\mathrm{x}$-ray fluorescence techniques (Weisler 1998). Obsidian flakes were recovered from the upper Plainware levels and again need to be geochemically sourced. Interestingly, obsidian was not recovered from the initial Lapita occupation levels or within the early Polynesian Plainware occupation levels. This absence is intriguing, for if basalt is being procured from local sources and exchanged predominantly within Tonga, as well as the local production of pottery, then this might suggest relatively isolated societies during the Lapita and early plainware periods. The appearance of obsidian in a very late ceramic context potentially suggests new interaction, albeit still Tongan, especially if the obsidian is sourced to Tafahi. If that is the case, this would imply the integration of a Tongan polity along the axis of the archipelago facilitating internal development with no significant outside cultural intrusions.

\section{Radiocarbon Samples}

Three wood charcoal samples from Falevai (Table 4) were radiocarbon dated (see Burley and Connaughton in press). None were identified to species. The samples occurred as small concentrations of flecks or chunks within sealed stratigraphic contexts. All dates are AMS measurements. Samples were submitted to the Center for Accelerator Mass Spectronomy (CAMS), the Lawrence Livermore National Laboratory, Davis, California. Calibrations were carried out using CALIB 5.1 radiocarbon calibration program (Stuiver and Reimer 2005). The Southern Hemisphere calibration curve, SHCa104, was applied (McCormac et al. 2004). Falevai presents a unique case within Tonga as it appears to have been settled during the Lapita / Polynesian Plainware transition where dentate-decorated Lapita ceramics were beginning to disappear. The radiocarbon dates of $2685 \pm 35 \mathrm{BP}$ (CAMS 119696) and $2645 \pm 35$ BP (CAMS 119695) provide a benchmark for the loss of decorated ceramics at Falevai and the continuation of plainware pottery manufacture. Interestingly, this is approximately 100 years earlier than occurs in Ha'apai and Tongatapu (Burley this volume). A detailed analysis of the plainware assemblage from both the Lapita and the Polynesian Plainware occupation strata will further aid our understanding of 
Table 4. Radiocarbon Dates from Falevai (after Burley and Connaughton, in press).

\begin{tabular}{|c|c|c|c|c|c|}
\hline Falevai & Date & Unit & Level & Stratum & Description \\
\hline CAMS 119694 & $\begin{array}{r}2500 \pm 35 \\
\delta 13 C-27.9\end{array}$ & 4 & 11 & III & $\begin{array}{l}\text { Charcoal, } 105 \mathrm{~cm} \text { below surface, associated with the Polynesian } \\
\text { Plainware occupation level. } 2686-2362 \mathrm{cal} \text { BP }(1 \sigma), 2704- \\
2356 \text { cal BP }(2 \sigma) \text {, median probability } 2503 \mathrm{cal} \mathrm{BP.}\end{array}$ \\
\hline CAMS 119695 & $\begin{array}{l}2645 \pm 35 \\
\delta 13 C-28.2\end{array}$ & 9 & 15 & III & $\begin{array}{l}\text { Charcoal, } 145 \mathrm{~cm} \text { below surface, associated with the Polynesian } \\
\text { Plainware occupation level. } 2759-2620 \mathrm{cal} \text { BP }(1 \sigma), 2778- \\
2501 \text { cal BP }(2 \sigma) \text {, median probability } 2729 \mathrm{cal} \mathrm{BP.}\end{array}$ \\
\hline CAMS 119696 & $\begin{array}{l}2685 \pm 35 \\
\delta 13 C-27.9\end{array}$ & 10 & 18 & IV & $\begin{array}{l}\text { Charcoal, } 180 \mathrm{~cm} \text { below surface, associated with the } \\
\text { Lapita occupation level. } 2777-2735 \mathrm{cal} \text { BP }(1 \sigma), 2844- \\
2622 \text { cal BP }(2 \sigma) \text {, median probability } 2755 \mathrm{cal} \text { BP. }\end{array}$ \\
\hline
\end{tabular}

the archaeological record to help tease out such particulars. Nonetheless, at $2 \sigma$, this time period substantially overlaps with Lapita dates from other sites in Vava'u (see Burley and Connaughton in press), indicating that the disappearance of decorated ceramics may have been a rapid event shortly after initial Lapita settlement.

The third date from Falevai, $2500 \pm 35$ BP (CAMS 119694), is affected by the calibration curve flattening for the interval 2530-2420 BP resulting in multiple calibration curve intercepts and substantially widening the calibrated age range (Burley and Connaughton in press). This is a major problem with dating of post-Lapita sites generally and specifically later Polynesian Plainware occupations. These plateaus have not helped archaeologists to accurately map the transition from Lapita to Plainware, especially when attempting to characterise later plainware ceramic assemblages up until the abandonment of pottery. With respect to the two earlier dates, this third date suggests a later event based on the fully plainware assemblage associated with these strata from Falevai. Exactly how much later is impossible to tie down given the affects of the calibration curve flattening. This does not mean that the late part of the ceramic sequence is missing. As mentioned above, due to the paucity of recovered sherds in the very upper levels of Stratum III and Stratum II as a whole, these levels potentially demarcate the aceramic period when pottery production was abandoned in Tonga.

\section{Conclusion}

How early specifically Polynesian societies adapted and developed within their island environments is of considerable interest in Oceanic studies. This paper provides an initial overview from Falevai, which can now be situated in the wider debate regarding the emergence of Ancestral Polynesian Society during the Lapita/ Polynesian Plainware transition in Tonga. Radiocarbon dates have been provided and discussed in conjunction with the stratigraphy encountered at Falevai in order to establish the context in which this site was occupied. Initial ceramic vessel forms are described but further analysis is currently being conducted.

Smith (2002:135) has argued that the transition from decorated Lapita to fully Polynesian Plainware vessels does not signal significant social change nor do plainware ceramics provide a satisfactory correlate for the appearance of a distinctly different society in West Polynesia. Furthermore, Smith (2002:180) has asserted that Polynesian Plainware assemblages show little, if any, change through time. However, considering the Polynesian Plainware phase encompasses a millennium or so of pottery production, it seems highly unlikely that plainware vessel forms do not change across time and space to some degree in Tonga. This is certainly the impression gleaned from the preliminary analysis of the Falevai ceramic remains as outlined here.

My research once complete is aimed at providing a more in-depth and detailed study of the complete plainware ceramic assemblage from the beginning of the Polynesian Plainware phase to the point at which 
pottery production ceases altogether. Additionally, I plan to profile the vessel forms that were being utilised at the end of the sequence in Tonga and compare them with other pottery traditions in West Polynesia just before the abandonment of pottery production. This will provide a better assessment of cultural similarities and differences through time amongst island societies.

If Polynesian culture did develop in Western Polynesia following initial Lapita settlement then the evidence for such social and economic change has a good chance of being identified in the archaeological record. More detailed investigation of targeted sites of this period is clearly a priority as noted by both Kirch and Green (2001:83) and Smith (2002). By closely examining the plainware ceramic sequence that is claimed to be associated with Ancestral Polynesian Society, we can further evaluate the strength of the argument for internal development predicated upon isolation from outside pottery making communities. However, as outlined earlier, pottery is but a single avenue of inquiry and other aspects of cultural and social change such as settlement and subsistence patterns, site distribution, and population growth must have had significant influence in the emergence and development of an Ancestral Polynesian Society. It is only with the compilation and assessment of such relevant data that we will be able to construct a more holistic and robust view of proto-Polynesian culture in Tonga.

\section{Acknowledgements}

Fieldwork was made possible by Dr. David V. Burley through a research grant from the Social Sciences and Humanities Research Council of Canada. I gratefully acknowledge his support as well as commenting on my initial draft of this paper. Gratitude is given to the Government of Tonga for assistance and support, in particular, the late 'Akauola, Governor of Vava'u. A giant malo aupito goes to the people of Falevai, whose generosity, support and interest in my project allowed me to enjoy every single moment under the sun with them. Particularly, I thank my field crew: Peau Halaingano, Peni Latu, Amelani Subuya, Sione Niu, Tomasi To'oa, Tonga Kemo e 'atu, Taukave Hakalo, Viliami Leakona, Ofa Blake and Solo Mone Hala e 'ioa. I also thank Dr. George Nicholas for editing an earlier draft, Jessi Witt for her preparation of the figures and comments on an earlier draft of this paper and David Burley and Christophe Sand for further critical comment.

\section{References}

Burley, D.V. 1998. Archaeology and the Tongan past; 2850-150 BP. Journal of World Prehistory 12:337-392.

Burley D.V. 2005. Mid-Sequence Archaeology at the Sigatoka Sand Dunes with Interpretive Implications for Fijian and Oceanic Culture History. Asian Perspectives 44(2):320-348.

Burley D.V. in press. Archaeological Demography and Population Growth in the Kingdom of Tonga-950 BC to the Historic Era. In P.V. Kirch and J. Rallu (eds), Long Term Demographic Evolution in Oceania. Honolulu: University of Hawaii Press.

Burley, D.V. and S.P. Connaughton in press. First Lapita settlement and its chronology in Vava'u, Kingdom of Tonga. Radiocarbon 49(1).

Burley, D.V. and W.R. Dickinson 2001. Origin and Significance of a Founding Settlement in Polynesia. PNAS 98 (20):11829-11831.

Burley, D. V., A. Storey and J. Witt 2002. On the Definition and Implications of Eastern Lapita Ceramics in Tonga. In S. Bedford, C. Sand, and D.V. Burley (eds), Fifty Years in the Field. Essays in Honour and Celebration of Richard Shutler, Jr's Archaeological Career, pp. 213-227. Auckland: New Zealand Archaeological Association Monograph 25. 
Dye, T. S. 1996. Early eastern Lapita to Polynesian plainware at Tongatapu and Lifuka: An exploratory data analysis. In J. Davidson, F. Leach, A. Pawley, and D. Brown (eds), Oceanic Culture History: Essays in Honour of Roger Green, pp. 461-473. Dunedin: New Zealand Journal of Archaeology Special Publication.

Flannery, K. V. and J. Marcus (eds) 1983. The Cloud People: Divergent Evolution of the Zapotec and Mixtec Civilizations. New York: Academic Press.

Green, R. C. 1972. Revision of the Tongan sequence. Journal of the Polynesian Society 81:79-86.

Green, R. C. 1986. Some basic components of the Ancestral Polynesian settlement system: Building blocks for more complex Polynesian societies. In P.V. Kirch (ed.), Island Societies: Archaeological Approaches to Evolution and Transformation, Cambridge: Cambridge University Press.

Green, R. C. and J. M. Davidson (eds) 1969. Archaeology in Western Samoa, vol. 1. Auckland: Auckland Institute and Museum, Bulletin 6.

Groube, L. 1971. Tonga, Lapita pottery and Polynesian origins. Journal of the Polynesian Society 80:278-316.

Hally, D. J. 1983. Use Alteration of Pottery Surfaces: An Important Source of Evidence for the Identification of Vessel Function. North American Archaeologist 4:3-26.

Kirch, P. V. 1984. Evolution of the Polynesian Chiefdoms. Cambridge: Cambridge University Press.

Kirch, P. V. 1988. Niuatoputapu: The Prehistory of a Polynesian Chiefdom. Seattle: Thomas Burke Memorial Washington State Museum, Monograph No. 5.

Kirch, P. V. 1997. The Lapita peoples: ancestors of the Oceanic world. Blackwell: Cambridge, Mass.

Kirch P. V. 2000. On the Road of the Winds: An Archaeological History of the Pacific Islands before European Contact. Berkeley: University of California Press.

Kirch, P.V. and R.C. Green 2001. Hawaiki, Ancestral Polynesia: An Essay in Historical Anthropology. Cambridge: Cambridge University Press.

McCormac, F.G., H.G. Hogg, P.G. Blackwell, C.E. Buck, T.F.G. Higham and P. J. Reimer 2004. SHCa104 Southern Hemisphere calibration, 0-11.0 cal kyr BP. Radiocarbon 46(3):1087-1092.

Poulsen, J. 1987. Early Tongan Prehistory: the Lapita period on Tongatapu and its Relationships. Canberra: Department of Prehistory, Australian National University. Terra Australis 12.

Rice, P. M. 1987. Pottery Analysis: A Source Book. Chicago: University of Chicago Press.

Sapir, E. 1916. Time Perspective in Aboriginal American Culture: A Study in Method. Ottawa: Government Printing Bureau. Department of Mines, Geological Survey Memoir 90 Anthropological Series 13.

Smith, A. 2002. An archaeology of West Polynesian Prehistory. Canberra: Pandanus Books. Terra Australis 18.

Spennemann, D.H.R. 1989. 'Ata 'a Tonga mo 'Ata 'o Tonga: Early and Later Prehistory of the Tonga Islands. Unpublished PhD thesis, Australian National University.

Steadman, D.W., G.K. Pregill and D.V. Burley 2002a. Rapid prehistoric extinction of iguanas and birds in Polynesia. PNAS 99(6):3673-3677.

Steadman, D.W., A. Plourde and D. V. Burley 2002b. Prehistoric Butchery and Consumption of Birds in the Kingdom Of Tonga, South Pacific. Journal of Archaeological Science 29:571-584.

Stuiver, M. and P.J. Reimer 2005. Radiocarbon calibration program CALIB rev. 5.1. < http://calib.qub. ac.uk/calib $>$.

Taylor, W. W. 1948. A Study of Archaeology. Menasha, WI: American Anthropological Association Memoir 69.

Weisler, M. 1998. Hard evidence for prehistoric interaction in Oceania. Current Anthropology 39:529-532. 